\title{
Trust Maintenance and Trust Repair
}

\author{
Liangtie Dai, Yujie Wu \\ Management School, Jinan University, Guangzhou, China \\ Email: 908608480@qq.com
}

Received 9 April 2015; accepted 15 May 2015; published 18 May 2015

Copyright @ 2015 by authors and Scientific Research Publishing Inc.

This work is licensed under the Creative Commons Attribution International License (CC BY).

http://creativecommons.org/licenses/by/4.0/

(c) (1) Open Access

\begin{abstract}
As an important social capital, construction and development of initial trust have been paid much attention. Trust violation, as a significant phenomenon, also begins to absorb many concerns. Studies of trust repair started late, and focused on sociology for analyzing trust crises during the social transition period in China, but seldom cared about individual and organizational levels. This paper, based on perspective of psychology, summarizes the definition, theoretical foundation and integrative model of trust, and discusses the trust violation, repair processes, repair strategies, the attribution model and dynamic bilateral model of trust repair, providing convenience for research in the individual or organizational level of trust repair.
\end{abstract}

\section{Keywords}

Trust, Trust Violation, Trust Repair

\section{Introduction}

In addition to physical capital and human capital, "trust" is generally considered as a main social capital of a country's economic growth, which can reduce transaction costs and promote economic development. Interpersonal trust level affects interpersonal relationships and the level of cooperation and working conditions. However, level of interpersonal trust is not consistent after its construction. Interpersonal trust is at risk, fragile and relatively vulnerable. Interpersonal trust is a very important topic. In recent years, Western scholars have turned to focus on repair method of trust and have achieved fruitful results, and they begin to make efforts to build trust repair model.

\section{Trust}

\subsection{Definition of Trust}

Trust is an expectation and mentation. Trustor takes action on the basis of this expectation, but trustee may take action contrary to this expectation. Therefore, trustor is risk-taking on the basis of this expectation to take action. 
McAllister (1995) distinguish trust as affective and intellectual types. Trust based on cognition is resulting from rational thinking while trust based on emotion is resulting from emotional connection between people. Distinction of trust has broken the previous understanding of it which is no longer just product of "rational calculation". Research and theory have begun to focus on the role of emotions in trust relationship. Nowadays, the most commonly accepted definition of trust is the definition proposed by Mayer, Davis, \& Schoorman (1995). In addition to expectation, trust is concerned the desire of risk-taking. Trust is ignorance of the ability of monitoring, that trustor expects trustee completing the action that is significant to trustor who must undertake the result of it and this expectation make trustor becoming disadvantaged groups.

\subsection{Theoretical Foundation of Interpersonal Trust}

\subsubsection{Transaction Cost of Economic Theory}

The premise of economics research in trust is the "economic man" hypothesis. Research methods include transaction cost method, principal-agent method, contract method, game method and so on. The first three methods are related to the principal-agent relationship, contract and transaction costs, because the principal-agent relationship requires constraint contract, while implementing the contract takes costs. In general, the transaction cost theory (principal-agent theory, contract theory) usually accompanied by game theory and the combination of both are between the trust analysis of individual and organization. Economic exchange relationship mainly refers to trade relationship based on rational calculation. This theory suggests that interpersonal interaction affected by maximizing the benefits and minimizing costs. Contact that defines the rights and obligations is necessary to supervise and control.

\subsubsection{Social Exchange Theory}

Social exchange theory produced in the late 1950s. Social exchange is a long-term investment, for example return of emotional cultivation and intelligence investment need a longer time. With respect to the economic exchange relationship, social exchange relationship is that the main consideration of meeting obligation is not immediate interests, but expecting that the other side will give an adequate return in the way of long-term consideration. The main theoretical points are as follows: 1) the reason why people engage in and maintain exchange relationship is rewards. Such return can be internal or external. Therefore, it goes beyond the rational assumption that people only seek tangible rewards; 2) to become someone else's exchange objects, one must demonstrates the benefits he/she may bring that is the return the other side pursues; 3 ) according to the points of two theories above, the exchange must be mutually beneficial to each other, that is to give each other a return. Typically, the return is not performed simultaneously with the exchange. Once the A benefited from B, B will believed he/she will be benefited from A, so that the two sides establish a sense of trust; 4) if both sides have obtained the anticipated return, this exchange relationship will strengthen the emotional bond between two sides.

\subsection{Integrative Model}

Mayer, Davis, \& Schoorman (1995) proposed an integrative model of trust. Trust is a process of interaction. Characteristics of both sides will affect the level of trust so that the level of trust of trustee in the model is determined by two factors: the reliability of trustee and the trust propensity of trustor. Ability, benevolence and Integrity are the factors affecting reliability. When one chooses to trust others, he/she usually pays some costs first, such as money, care, helping behavior and so on. However, these behaviors may not be able to get the expected return, which is a risk for the individual. The trust is that while one admitting and accepting this risk, he/she still chooses to trust. Trust makes the individual passive, because even the safety of his interests is vested in the hands of others. The individual has a will to be weak. The final result of trust depends on whether the individual trusts each other and on each other's feedback behavior. If the other's behavior is in accordance with the expected action, then trust will get good results while if not, trust will bring harm. The model is shown in Figure 1.

Schoorman, Mayer, \& Davis (2007) concluded that the basis of integrative model is to understand how individual process the information of others and decide whether to take the risk of trust on the basis of it. Integrative model stresses that trust is a product of reason. But in fact, the trust is not entirely rational results, and the feelings among people are common. Lewis \& Weigert (1985) suggest that interpersonal trust can be divided into basing on cognition and emotion. McAllister (1995) performed a research that how cognitive trust and emotional trust affect organizational performance and verified that trust can be divided into cognitive trust and emotional trust. 


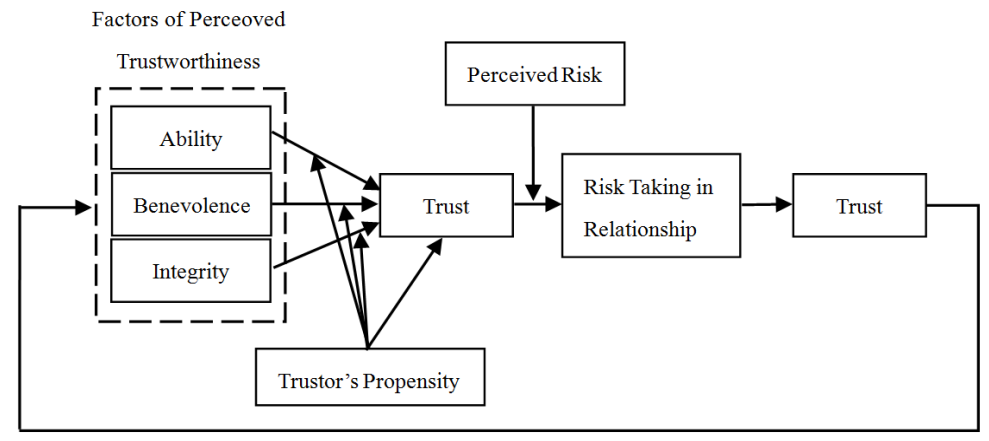

Figure 1. Integrative model (Mayer, Davis, \& Schoorman, 1995).

\section{Trust Repair}

\subsection{Theoretical Model of Trust Repair}

\subsubsection{Attribution Model}

On the basis of emotion and motivation attribution model proposed by Weiner (1986), Tomlinson \& Mayer (2009) put forward the trust repair attribution model and a series of specific trust repairing strategy. The model indicates that, after trustee destroyed the trusty cognition of trustor, trustor will automatically determine the cause of this result. In this attribution level, the attribution of trustor to trustee's behavior is mainly divided into four categories: ability, kindness, integrity of trustee and other reasons. The other reason is not related to trustee while ability, kindness and integrity are the three trusty dimensions of trustee. Specifically, ability refers to the talents and skills of trustee; kindness is that the motivation of trustee is not for their personal interests but to achieve the interests of the trustor; integrity is trustee keeping a series of standards of behavior trustor accept.

Then, the trustor will attribute these factors on a deeper level. Attribution on level includes three dimensions: source of reason, controllability and stability. The reasons can be divided into internal source (i.e. cause of the negative result is trustee) and external source (i.e. cause of the negative result is individuals or situations). In other words, the source of reason refers to individual or situation responsible for the result; controllability refers to degree of one controlling the behavioral result; stability refers to the possibility of a specific result repeating again in similar circumstances.

On the basis of the above model, Tomlinson \& Mayer (2009) described the trust repair strategy. When a negative consequence of an action has reduced or event completely destroyed judgment of trust of trustor to trustee, trust repair can be conducted by trustee proving that the reason of this consequence is external. In addition, the trustee may also adopt other means. Specifically, when trustor lost confidence in trustee's ability, trust repair can be conducted by trustee proving that the ability factor resulting in this consequence was controllable and stable. Similarly, when trustor lost confidence in trustee's kindness, trust repair can be conducted by trustee proving that the reason resulting in this consequence was an unstable and inner ability factor or an accidental and low level of kind behavior. In the same way, when trustor lost confidence in trustee's integrity, trust repair can be conducted by trustee proving that the negative result was caused by an unstable internal factor.

In addition to cognitive trust repair strategy, attribution model also explicitly pointed out that the effect of emotional factors on the consequence of trust repair. According to this model, negative emotions of a negative result of the trustor are an important factor to attribute the result, such as anger and fear. Anger is usually related to the controllability of result and fear is related to stability of result. In addition, these negative emotions will affect the cognition of credibility of trustor to the trustee, which seriously hinder the trust repair. Therefore, before and in the middle of the implementation of trust repair strategy, trustee should try to comfort and ease the negative emotions of trustor by various means to ensure the effectively repair judgment of trust of trustor to trustee.

\subsubsection{Bilateral Model of Trust Repair}

Kim, Dirks, \& Cooper (2009) established BTR from the perspective of cognition and pointed out that the trust repair is not a simple single process that actions only taken by trustee but trustor only passively observes and evaluates trustee's attempt of repair to be trusted. On the contrary, they think, in process trust repair, trustor and 
trustee both play a very important role. The success of trust repair depends not only on whether trustor accept the repair behavior of trustee, but also depends on the action the taken to repair the trust. Therefore, Kim, Dirks, \& Cooper (2009) put forward three important assumptions about the trust repair: 1) trustee hope that others consider he/she can be trusted; 2) trustor tends to think that the trustee should not get more trust; 3 ) both the trustor and trustee try to solve conflicts.

The above three hypotheses primarily reflect the dynamic and bilateral of trust repair process. In addition, they also pointed out that consequence of trust repair is various. Such as the successful repair, confrontation, confirmed judgment of not being worth trusting and avoiding repair. Result of trust repair depends on the efforts of trust repair made by trustor and trustee (Figure 2). The trustee must take actions to prove himself worthy trust and the efforts must be greater than the degree of trustor resisting repair trust.

On this basis, the model discussed how trustee prove his/she is credibility to trustor and make his/he efforts greater than the degree of trustor resisting repair trust to the level of successful trust repair (Figure 3). The theoretical framework of the model consists of three interrelated parts. First of all, the first level of the model shows that trustee should try to prove repair his innocence in the process of trust repair. This positive behavior of repair trust will greatly influence trustor's perception of credibility to trustee and this may subvert the disadvantaged judgement of trustor. On the contrary, trustor tends to refuse to accept or resist trustee's explanation and insist on his/she previous judgement that trustee made some mistakes and he/she is trustless.

On this process of trust repair, trustee can prove his/her innocence through a variety of ways. These methods can be divided into two tangible and intangible categories. The tangible way is trustee provides specific and effective evidence while and intangible way is trustee's oral denials. For the other side of the bilateral model trustor are not just passively judge and evaluate the trustee's repair behavior and the degree of effort. The former's behavior and attitude can largely affect the degree of trustee's repair effort, and sometimes even force trustee to give up the will and efforts to restore trust. As mentioned above, in order to successfully repair trust, trust repair effort of trustee must be greater than trustor's resistance of this effort. In other words, successful trust repair depends on the "net effort" of the trust repair behavior of both turstor and trustee. If trustee failed to confirm

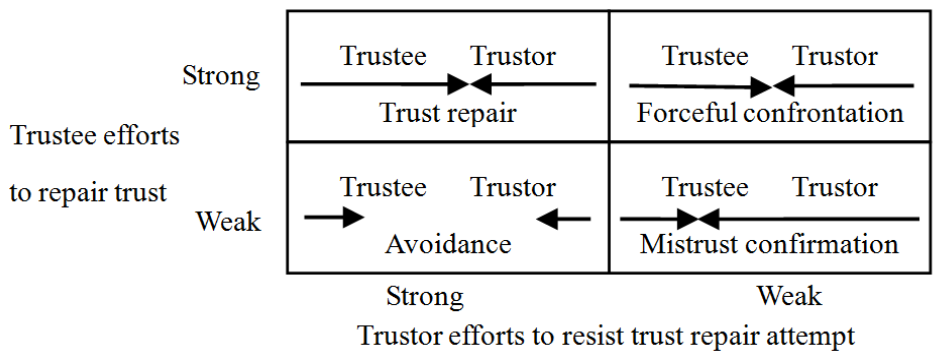

Figure 2. Potential outcomes of negotiation efforts by a trustor and trustee (Kim, Dirks, \& Cooper, 2009).

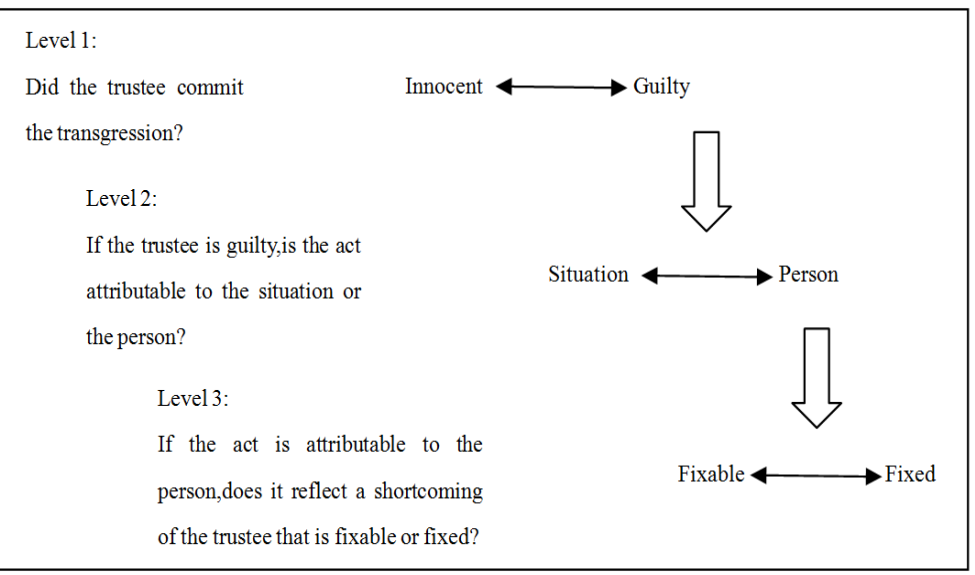

Figure 3. Bilateral model of trust repair (Kim, Dirks, \& Cooper, 2009). 
his/her credibility in this process, then it should also take the necessary action to alleviate the trustor's negative perception of the credibility to trustee.

Similar with the attribution model, the theoretical basis of BTR model of the other two levels is the attribution theory. Specifically, the second level of the model emphasizes the attribution of source of behavior, namely the internal attribution (trustee) and external attribution (situation). The third level of the model represents on the stability of the attribution of cause, namely the cause is variable or fixed. That is to say, if the trustee could not confirm they have no responsibility for the results, he/she can confirm the cause of the consequence is external factors (context), so as to repair the trust in a certain extent. If the trustee is unable to provide effective evidence that the causes of negative outcome is external, then he/she must prove to trustor that the internal factor is unstable which can be changed, in order to show that similar situation can be avoided in the future.

The advantages of BTR is that it pointed out and emphasized the status and role of trustor in the process of trust repair and successful trust repair depends on the "net effort" of the trust repair behavior of both turstor and trustee.

\subsection{Strategy of Trust Repair}

Trust repair refers to after the destruction of interpersonal trust relationship was destroyed, the action taken by trustee in order to repair trust.

\subsubsection{Apology}

Trustee admits that violation behavior is his/she mistake and feels regret and guilt, willing to take responsibility and hoping to get the understanding of trustor. Apology can positively affects the evaluation of trustor on trustee's motivation and reduces the worry which trustor will continue to be hurt the fear, which can improves the level of trust of the trustor. Research on trust repair includes two aspects: trust belief and trust behavior. Effect of trust repair is reflected in whether belief and trust behavior have changed.

There are a large number of research results show that apology can repair the belief of trustor on trustee. For example, Kim et al. (2004)'s experiment in scenario shows that when trust violation competence based occurs, the apology's repair effect of trustor's belief on trustee is better than denial. Carlisle et al. (2012) found that apology leads to more forgiveness. That is to say, participants were more willing to forgive those who make an apology response in the attitude. This indirectly proves the effect of apology in repairing trust belief.

The existing research results in effect of apology in repairing trust belief is not consistent. Haselhuhn, Schweitzer, \& Wood (2010) using the trust game to explore how the implicit belief effects trust repair, when the participant obtain apology of unfair distribution and commitment of cooperation from the destroyer, participants choose to assign money to destroyer, namey trust behavior increases significantly. Schweitzer, Hershey, \& Bradlow (2006) found that, the trust game, simple saying sorry cannot increase turst behavior of trustor on trustee. This may be because trustor may consider destroyer simpley saying sorry as perfunctory, not sincere behavior. Researchers found that compared to apology, when their own interests are involved, the effect of economic compensation is more obvious.

\subsubsection{Denial}

The one who violates the trust denies that the violation behavior related to he/she and attribute the violation behavior to other reasons and don't assume any responsibility.

Denial is divided into direct and indirect denial. Direct denial is that the party claims that other's facts or reasons are not true and directly deny it. Indirect denial is that the party claims fact from a positive aspect and find out the "scapegoat" to in directly deny the facts and reasons proposed by others. The party does not bear responsibility and feel so guilty.

\subsubsection{Promise}

The relationship between the people engaged in an activity, individual of one side make promise to his job. Once you make a promise it is binding. This binding comes from the pay to breach. For example, economic loss in the process of fulfilling their commitment, loss of reputation, social and moral condemnation, legal punishment and so on.

\section{Conclusion}

This paper, under the background in psychology, considers that trust is a kind of expectation and that trustor 
takes actions based on this expectation. Interpersonal trust is based on the theoretical basis of economics and sociology and the main consideration of interpersonal interaction not only is the immediate vested interest but also needs to take long-term expectation to expect appropriate reward given by others. Integrative model of trust illustrates the influence of ability, benevolence and integrity on interpersonal trust and makes attribution to latter trust model. However, in the process of trust repair, trustee is not passive recipient and evaluation object. BTR adds the role of trustor and trustee in trust repair, the stage of trust repair and the strategy of trust repair to the model providing convenience for the individual or organizational level of trust repair in the future.

\section{References}

Carlisle, R., Tsang, J., Ahmad, N. et al. (2012). Do Actions Speak Louder than Words? Different Effects of Apology and Restitution on Behavioral and Self-Report Measures of Forgiveness. The Journal of Positive Psychology, 7, 294-305. http://dx.doi.org/10.1080/17439760.2012.690444

Haselhuhn, M., Schweitzer, M., \& Wood, A. (2010). How Implicit Beliefs Influence Trust Recovery. Psychological Science, 21, 645-648. http://dx.doi.org/10.1177/0956797610367752

Kim, P. H., Dirks, K. T., \& Cooper, C. D. (2009). The Repair of Trust: A Dynamic Bilateral Perspective and Multilevel Conceptualization. Academy of Management Review, 34, 401-422. http://dx.doi.org/10.5465/AMR.2009.40631887

Kim, P. H., Ferrin, D. L., Cooper, C. D., \& Dirks, K. T. (2004). Removing the Shadow of Suspicion: The Effects of Apology versus Denial for Repairing Competence- versus Integrity-Based Trust Violations. Journal of Applied Psychology, 89, 104-118. http://dx.doi.org/10.1037/0021-9010.89.1.104

Lewis, J. D. and Weigert, A. (1985). Trust as a Social Reality. Social Forces, 63, 967-985. http://dx.doi.org/10.1093/sf/63.4.967

McAllister, D. J. (1995). Affect- and Cognition-Based Trust as Foundations for Interpersonal Cooperation in Organizations. Academy of Management Journal, 38, 24-59. http://dx.doi.org/10.2307/256727

Roger, C., Davis, M. F., \& Schoorman (1995). An Integrative Model of Organizational Trust. Academy of Management Review, 20, 709-734.

Schoorman, F. D., Mayer, R. C., \& Davis, J. H. (2007). An Integrative Model of Organizational Trust: Past, Present and Future. Academy of Management Review, 32, 344-354. http://dx.doi.org/10.5465/AMR.2007.24348410

Schweitzer, M., Hershey, J., \& Bradlow, E. (2006). Promies and Lies: Restoring Violated Trust. Organizational Behavior and Human Decision Process, 101, 1-19. http://dx.doi.org/10.1016/j.obhdp.2006.05.005

Tomlinson, E. C. and Mayer, R. C. (2009). The Role of Causal Attribution Dimensions in Trust Repair. Academy of Management Review, 34, 85-104.

Weiner, B. (1986). An Attributional Model of Motivation and Emotion. New York: Springer-Verlag. http://dx.doi.org/10.1007/978-1-4612-4948-1. 